\title{
Relationships Between Demographic Factors and Employment Prospects of Architecture, Construction and Urban Planning Graduates
}

\author{
Joanna Poon, BSc (Hons), MSc, MA, PhD, MCIOB, FHEA \\ School of the Built Environment, \\ University of Salford, M5 4WT, Greater Manchester, UK \\ Email: j.1.k.poon@salford.ac.uk
}

\begin{abstract}
This paper investigates the relationships between demographic factors and the employment prospects of architecture, construction and urban planning students. Dimensionality reduction was used to produce the dataset for the further analysis in this paper from the raw data of Australia Graduate Survey (AGS). Descriptive analysis, chi-squared contingency 2-way analysis and phi-coefficient test were used for the analysis of data. The research findings indicated that architecture graduates have the lowest level of graduate employment at $84.66 \%$ whilst construction graduates have the highest level at $92.27 \%$. Gender, age and education level are not statistically significant correlated with whether the graduates are able to secure employment after graduation. On the other hand, whether speaking English at home or not is statistically significant correlated with whether graduates secured employment or not after graduation. Demographic factors are statistically significant correlated with whether graduates secure full-time or part-time employment. Architecture graduates who are male, age 24 years or above, studied a postgraduate degree and spoke English at home are more likely to be employed on a full-time basis after graduation. Age and whether speaking English at home or not; and gender are not correlated with whether construction and urban planning graduates respectively were employed full-time.
\end{abstract}

Key words: Architecture, Australian Graduate Survey, Construction, Demographic Factors, Employment Prospects, Urban Planning

\section{Introduction}

Australian government studies illuminate the country's concern about the employment rates of post-secondary graduates (DEST, ACCI and BCA, 2002; DIICCSRT, DEEWR and CSfW, 2013; Precision Consultancy, 2007). Gaining employment is considered a key factor in measuring the success of a university degree level education. Therefore, there is a need to examine the factors that enhance a graduate's employment prospects.

The aim of this research is to identify the impacts of demographic factors on graduates' employment prospects, such as whether architecture, construction and urban planning graduates in Australia gained employment or not and whether they have secured full-time or part-time jobs. This paper adopted the same categorization of graduates as the AGS classifications, which includes undergraduate and postgraduate levels. Undergraduate level includes the following courses: Diploma or Advanced diploma, Bachelor degree (graduate entry), Bachelor degree (honours) and Bachelor degree (not honours or graduate entry) whilst postgraduate level includes Graduate certificate, Graduate diploma and Master degree by coursework. Postgraduate students as mentioned in this paper are the students who studied in Graduate School in the USA context. As this study focused on investigating the employment prospects of graduates from taught degree courses only, the graduates who studied postgraduate research degree programmes were excluded in this study. This paper will address the following research questions: 
- What are the differences in the demographic factors for architecture, construction and urban planning graduates?

- What are the differences in the demographic profiles of employed and unemployed architecture, construction and urban planning graduates in Australia?

- What are the differences in the demographic profiles of part-time and full-time employed architecture, construction and urban planning graduates in Australia?

\section{Demographic Factors Affecting Graduate Employment}

Gender is one of the most influential demographic factors on graduate employment (Artess et al., 2008; Connor et al., 1997; Dainty et al., 2000; Smith et al., 2000). McKnight (1999) identified gender as one of the factors affecting graduates' early career trajectories, based on the result of a survey of approximately 11,000 graduates in 1995 from 33 higher education institutions in the UK which tracked their early career paths over the first three and a half years. This finding is also reinforced by the study conducted by Smith et al.'s (2000), which is based on the official data for First Destination Survey (FDS), conducted by Careers Offices of each university and deposited with the Higher Education Statistics Agency (HESA) in the UK. Male undergraduate leavers were more likely to be unemployed but at the same time a higher proportion of them worked in graduate level occupations (Elias et al., 1999 and Smith et al., 2000). This is the same case for postgraduate leavers. The previous research found that male graduates usually have a favourable salary difference and better career prospects as compared to the female graduates (Artess et al., 2008; Dainty et al., 2000 and Elias et al., 1999). Based on a study of women's employment opportunities and career progression patterns in large construction companies, Dainty et al. (2000) concluded that men and women experienced disparate career progression dynamics. Women were found to have a slower progression rate and have a greater number of obstacles to their professional development. The employment prospects of men and women also differed, with $92 \%$ of men being employed in full-time positions compared with only $55 \%$ of women. Furthermore, there are also more women employed in part-time positions than men at $43 \%$ and $2 \%$ respectively (IER, 1997). Fielden et al. (2000) further stated that women are more likely to be employed in secretarial and administrative posts, but not in professional roles within the construction sector. Fielden et al. (2000) identified the sources of barriers hindering women from having as successful a career as their male colleagues, such as the construction industry's image; career knowledge amongst children and adults; selection criteria and male dominated courses; recruitment practices and procedures; sexist attitudes; male dominated culture; and the work environment.

Age is another important factor affecting graduate employment (Artess et al., 2008; Devaney and Roberts, 2012; Smith et al., 2000; Urwin and Di Pietro, 2005). Smith et al. (2000) commented that men aged over 33 at graduation are 6 percentage points more likely to be unemployed or inactive than are men aged less than 24 at graduation. Smith et al. (2000) also commented that women who graduated aged between 24 and 33 are at least 2 percentage points more likely to be unemployed or inactive than younger female graduates. It is important to note that there is not a universal or constant age level mentioned in the previous studies. Therefore, the concluding note of this paragraph is that age has an impact on graduate employment prospects but there is no 
clear-cut age which can be considered as a 'definite' age having a threshold impact on graduates' employment potential.

English language ability has also been cited as one of the most important determinants for graduate employability (Dabalen et al., 2001; Lan, 2003; Lim, 2010). Lim (2010) commented that good English language proficiency gives an added advantage to university study, job application, and has a favourable impact on employment rates and reduces the number of days unemployed. It is definitely the case for countries that use English as a second language (Dabalen et al., 2001; Lan, 2003). In Malaysia, English is one of the official languages; the university changed the medium of instruction for science and mathematics courses in Malaysian public universities from Bahasa Melayu (the national language of Malaysia) to English in order to raise graduates' English standards.

Ethnicity has also been identified as another factor affecting graduate employment in previous literature (Casplan and Gilham, 2005; Lim, 2010). Lim (2010) commented that Malay graduates are consistently less favourable in the labour market as compared to the non-Malay graduates in Malaysia. Lim's (2010) research found that Chinese graduates are found to have a lower probability of being unemployed and have on average 49 days less unemployment than Malay graduates, which echoed Wong and Hamali's (2006) research findings. Casplan and Gilham's (2005) noted there is a marked difference between relatively high representation of minority ethnic groups on built environment courses in further and higher education and low representation in professional and managerial roles in these areas. Their study identified the structural and cultural factors that have prevented the minority ethnic professionals from following their career aims, and of the failure of the built environment industry more generally to be inclusive and diversify its workforce. The discussions and findings drew upon interviews with minority ethnic professionals, students, lecturers and employers working in Britain in construction, engineering, architecture, surveying, planning and urban and landscape design. In the USA, there were studies identifying the impact of demographic diversity on the job-related attitudes of Hispanic graduates (Guerrero and. Posthuma, 2014; Smith and Clark, 2011). Smith and Clark's (2011) research found that Hispanic graduates showed an increase in self-efficacy at work when there was an increase in the percentage of Hispanics in the community where they worked. Riordan and Shore (1997) also pointed out that Hispanics had positive job-related attitudes such as work group commitment, perceptions of work group productivity, and perceptions of advancement opportunities when participating in demographically diverse workgroups. On the other hand, if Hispanics worked in an environment which gave them lower access to well-paying jobs, they had lower loyalty, less willingness to work hard, negative perceptions of company fairness, and higher turnover intentions (Dickerson et al., 2010).

\section{Concluding remarks and identification of research gap}

Demographic factors, such as gender, age and English proficiency have been identified as having an impact on graduates' employment prospects. Male graduates who are younger and have better English proficiency are more likely to secure employment after graduation. Despite previous research having studied the impact on the level of education, i.e. undergraduate or postgraduate degree, on graduate employability, these studies mainly focused on either one type or the other in degree level. For example, Lim (2010), Smith et al. (2000) focused on studying undergraduate 
courses while Devaney and Roberts (2012) and Urwin and Di Pietro (2005) focused on investigating employability for graduates of postgraduate courses only. There is yet to have been a study to compare whether a different level of education has an impact on the employment prospects of graduates studying in built environment disciplines.

Devaney and Roberts (2012) conducted research on employability of property and construction graduates in the UK. Their research aimed to identify the type of demographic backgrounds of graduates who are more likely to gain employment. However, employment was defined in this paper as any job, regardless of whether it was full-time or part-time. Furthermore, Devanery and Roberts's (2012) research did not state clearly whether the targeted respondents in their research included only UK Permanent Residents or overseas students as well. Moreover, Devaney and Roberts's (2012) research did not exclude the graduates who declared they were continuing on to further study. The inclusion of these groups of graduates adds ambiguity to the analysis of graduate employment prospects. Graduates without residency are subject to legal limitations on seeking employment in foreign countries such as the UK or Australia and may be unlikely or unable to seek employment in the country where they studied.

Devaney and Roberts (2012) and Smith et al.'s (2000) studies used the UK government statistics on graduate employment while Ballarino (2009) used Italian government graduate employment statistics. Dainty et al. (2000) and Urwin and Di Pietro's (2005) research used primary research data collected in the UK. Lim's (2010) respondents were graduates from undergraduate degree programmes from the Faculty of Business in the University of Utara Malaysia. There is not yet any research with an Australian focus or using Australian official data for the research.

This research aims to fill this gap, which is to investigate the impact of demographic factors, such as age, gender, education level and English proficiency, on graduate employment prospects, including whether employed or unemployed and employed on a full or part-time basis. This paper will focus on the graduates who studied architecture, construction and urban planning. The reason for focusing on these subject areas is that there was no previous study focusing on comparing the graduates' employment prospects on these built environment disciplines.

\section{Research Methods}

\section{Data Source}

The data used in this paper has been collated from the Australian Graduate Survey (AGS) (AGS, 2015). AGS is a national census of newly-qualified higher education graduates that has been in operation since 1972. The survey is conducted approximately four months after the students have completed the requirements for their awards. The data used in this paper dated from 2010 to 2012.

Other similar studies conducted in the UK, such as Smith et al. (2000) and Devaney and Roberts (2012) also used the government statistics on graduate destination. Smith et al. (2000) used First Destination Survey (FDS), conducted by Careers Offices of each university and deposited with the Higher Education Statistics Agency (HESA) and Devaney and Roberts (2012) used HESA 
Destination of Leavers from Higher Education (DLHE) dataset. Davaney and Roberts (2012) used a four year longitudinal data (2005/06 to 2008/9) while Smith et al. (2000) has only used one year (1983) data. The current study used a similar type of government employment statistics of a three-year period.

\section{Discussion On The Quality Of Data}

Although the use of the AGS data for employment destination analysis faces similar issues as other research using government statistics, such as Smith et al. (2000) and the DLHE dataset by Davaney and Roberts's (2012) studies, the AGS is the most comprehensive graduate survey in Australia and provides detailed information on a large enough sample of university graduates to produce a statistically sound data analysis. The first problem for the AGS dataset is the incomplete response rate. The survey response rate for domestic graduates, which is the primary focus of the AGS, typically ranges from 60 to 65 per cent. There is no information on the response rate recorded for the overseas students. As a measure to overcome this problem, the current study only considers the employment prospects for the architecture, construction and urban planning graduates who declared themselves as Australian Permanent Residents when surveyed. Another reason for focusing on Australian Permanent Residents only is that overseas students have legal limitations in seeking employment in Australia and including them would potentially distort the results. The second problem is the timing of the survey conducted. The graduates are invited to complete the survey only four months after the completion of their courses, and this may be too early to conclude their employment situation. However, as stated by McKnight (1999), gaining employment within six months is a good indicator for measuring graduate labour market difficulties. Based on McKnight's (1999) study on the 1995 UK graduates employment destination, it indicated that graduates who remain unemployed after six months are typically unemployed for more than one year during the first three and a half years after finishing their degree. This compares with an average duration of unemployment of one month for graduates who were employed within six months of graduation. Unemployment at six months after graduation is also associated with a higher probability of being employed in a nongraduate occupation in the future (ibid.). Although the AGS survey is completed four months after the graduates finish their degree, it can still provide a useful indication of their employment prospects.

\section{Data Preparation}

Dimensionality reduction was used to prepare the dataset for further analysis in this paper, from the raw data of AGS. The R programming language was used to combine the three-year datasets of AGS data (2010-2012) into one dataset and perform further analysis (Field et al., 2012).

Dimensionality reduction was used to identify the courses which are grouped under architecture, construction and urban planning. For the architecture course identified in this paper, this includes Architecture and Interior and Environmental Design as stated in AGS. The construction course includes Construction Engineering, Building Science and Technology, Building Construction Management, Building Surveying and Building Construction Economics (including quantity surveying) as stated in AGS. Urban planning is a course of itself stated in the AGS data. In addition, the author also reviewed information contained in the columns, which states the graduates' Course Majors (up to four majors can be identified) and identifies the graduates who 
study courses related to architecture, construction and urban planning and included them into the respective groups together. If the graduates indicated that they were studying more than one course major, the author has grouped them according to information based on their Course Major One. In 2010-2012, there were 4156 students studying architecture, 2011 studying construction and 2117 studying urban planning.

Dimensionality reduction was used to produce the dataset for the education level and age classification of the graduates, i.e. below 24 or 24 or above. The reason for choosing 24 years old as a threshold was because the study included both undergraduate and postgraduate degree courses. The length of a Masters Degree in Australia is usually two years with graduates required to complete their survey about four months after graduation, so the majority of postgraduates would be at least 24 years old upon completion of their course. Therefore, 24 years old is considered as the minimum age to complete taught postgraduate degree, such as Master Degree, in Australia and it has been used as a threshold for dividing students with different age groups for the current research.

Although ethnicity has been mentioned as a key demographic factor affecting graduate employability in previous literature, it is not considered in this paper as the only ethnic information available in the AGS data was whether the graduate considered themselves an Aboriginal or Torres Strait Islander (ATSI). Because the number of ATSI students was very small, there were only 25 ATSI graduates out of all architecture, construction and urban design graduates who completed the AGS questionnaire from 2010 to 2012, there is not enough data to make a sound analysis.

The indicator of a graduate's English proficiency is whether the graduate stated that they spoke English at home for the relevant question in the AGS questionnaire. Language spoken at home is a demographic factor as it provides an indication as to whether English is the first language for the graduates.

This paper only includes the graduates who were Australian Permanent Residents. This paper also excludes the graduates who declared that they were continuing on to further study, as they were unlikely to seek full-time graduate level employment, in order to minimise the cause on the bias of results. After taking these into consideration, there were 2119, 1475 and 1522 architecture, construction and urban planning graduates respectively identified in this paper.

\section{Data Analysis}

Both descriptive and statistical analysis methods have been used to assess the impact of demographic factors on whether graduates were employed or unemployed and were full-time or part-time employed in this paper. Descriptive statistics techniques were used to identify the differences in the demographic profiles of employed and unemployed, and part-time and fulltime employed architecture, construction and urban planning graduates in Australia. Pivot tables were used to sort, count and summarise all the AGS data related to architecture, construction and urban planning graduates' who were employed or not and whether employed on a full-time or part-time basis and then create new tables to display the summarised data. The R programming language was also used to conduct the statistical analysis of this research. 
The next step is to identify the statistical significance of the impacts of the demographic factors including gender, age, education levels and whether the student spoke English at home or not, on whether the architecture, construction and urban planning graduates were employed or unemployed and were in full-time or part-time employment.

Chi-squared contingency 2-way analysis was used to conduct the data analysis in this research. The reason for using the 2-way analysis is to ensure the accuracy of the result. Also, the demographic variables considered in this paper are binary variables (Field et al., 2012). .

The phi coefficient was used to measure the correlation between being employed or unemployed and whether in full-time or part-time employment against individual demographic factors. The phi coefficient was chosen as it is designed for the comparison of truly dichotomous distributions, i.e., distributions that have only two points on their scale which indicate some unmeasurable attribute. The value of the phi correlation coefficient ranges from -1 to +1 , where $+/-1$ indicates perfect correlation between two variables and 0 indicates no relationship between two variables (Field et al., 2012).

The effect size of chi-squared test can be described by phi coefficient. The value of the phi coefficient is to demonstrate the strength of the relationship between two variables. The values for small, medium and large relationships between two variables are $0.10-0.30,0.30-0.50$ and larger than 0.50. If the value is smaller than 0.1, the effect size is considered to be trivial. However, if the phi coefficient is zero, which means no relationship exists between two variables (Cohen, 1988; Morgan et al., 2013). The importance of knowing the magnitude or size of effect enables the researchers to ascertain the practical significance of statistical significance. Effects of size can also reduce the reliance on focusing on significance testing only and it is especially significant for large sample size samples, like the current study.

\section{Research Findings And Discussions}

\section{Differences In The Demographic Factors For Architecture, Construction and Urban Planning Graduates}

The gender distribution for construction graduates was the most uneven with $83.19 \%$ of construction graduates being male. A slightly higher percentage of male architecture graduates, at $53.80 \%$ while slightly more urban planning graduates were female at $50.92 \%$. There was also a higher percentage of construction graduates studying undergraduate degree courses, at $85.76 \%$. On the other hand, there was a higher percentage of graduates studying postgraduate degrees for architecture and urban planning courses, at $55.21 \%$ and $51.58 \%$ respectively. There was a higher percentage of urban planning graduates over 24 years old, at $61.76 \%$, while there were higher percentages of architecture and construction graduates below 24 years old, at $54.32 \%$ and $58.03 \%$ respectively. The majority of graduates spoke English at home. Urban planning

graduates had the highest percentage, at $88.63 \%$, compared to $78.06 \%$ of architecture graduates.

\section{Differences In The Demographic Profiles of Employed and Unemployed Architecture, Construction and Urban Planning Graduates in Australia}


Among the three disciplines studied in this paper, construction graduates had the highest employment rate, at $92.27 \%$ (1361 graduates), as compared to $84.66 \%$ (1794 graduates) and $88.76 \%$ (1351 graduates) for architecture and urban planning respectively (see Table 1). This finding echoed Connor et al. (1997); Lim (2010); McKnight (1999) and Smith et al.'s (2000) research findings, that the degree subject is a factor influencing graduate employment.

\section{INSERT TABLE 1 HERE}

The employment rates for the architecture, construction and urban design graduates who spoke English at home were higher than those who spoke other languages at home. The employment to population ratios for the architecture, construction and urban planning graduates who spoke English at home are $87.55 \%, 93.52 \%$ and $89.92 \%$ as compared to those who spoke other languages at home, at $74.39 \%, 86.06 \%$ and $79.63 \%$ respectively (see Table 2).

\section{INSERT TABLE 2 HERE}

This also confirmed that speaking English at home was statistically significant correlated with whether architecture, construction and urban planning graduates were employed or unemployed as their chi-square p-values on speaking English at home all had the values of 0.00 (see Table 3). Their phi coefficient values for architecture, construction and urban planning graduates were $0.15,0.12$ and 0.10 (see Figure 1), which indicated there were moderate positive relationships between being employed or unemployed and the English proficiency of these graduates (Field et. al., 2012). This finding shares Dabalen et al. (2001), Lan (2003) and Lim's (2010) conclusion on the significance of English proficiency on gaining graduate employment.

\section{INSERT TABLE 3 HERE}

\section{INSERT FIGURE 1 HERE}

Female urban planning graduates were more likely to gain employment as their employment to population ratio was $91.10 \%$ as compared to $86.35 \%$ for the male counterparts (see Table 2). The male architecture and construction graduates had a slightly better chance to gain employment, with an employment to population ratio $0.20 \%$ and $1.37 \%$ higher than their female counterparts. However, the differences were not statistically significant as their chi-square p-values were 0.94, 0.36 and 0.30 , higher than the statistically significant level of 0.05 (see Table 1). This finding contrasts with the findings from Artess et al. (2008), Connor et al. (1997), Dainty et al. (2000), Elias et al. (1999), McKnight (1999) and Smith et al. (2000), which stated that, gender had an impact on whether graduates successfully secured employment or not. One of the possible explanations for this is that the economic outlook is better in Australia, as compared to the UK where most of the other similar studies were conducted. The unemployment rate in Australia is lower than the UK in general, leading to a higher employment rate for all graduates irrespective of gender.

Age was not statistically significant correlated with whether architecture, construction and urban planning graduates were employed or not as their chi-square p-values were $0.49,0.35$ and 0.78 , 
higher than the value for statistical significant level of 0.05 . The findings of this research are different from the findings of Artess et al. (2008), Connor et al. (1997), Devaney and Roberts (2012), McKnight (1999), Smith et al. (2000) and Urwin and Di Pietro (2005), which indicated age had an impact on graduate employability, the older graduates were more likely to gain employment after graduation .

Education level also was not statistically significant correlated with whether the architecture, construction and urban planning graduates were employed or not, as their chi-square and pvalues were $0.25,0.23$ and 0.56 , which indicated they were higher than the minimum value for statistical significant level of 0.05 .

\section{Differences In The Demographic Profiles Of Part-time And Full-time Employed Architecture, Construction And Urban Planning Graduates In Australia}

All demographic factors considered in this paper were statistically significant correlated with whether architecture graduates were in full-time or part-time employment. Architecture graduates who were male, over 24 years old, studying postgraduate degrees and speaking English at home were more likely to secure full-time employment after graduation. The employment to population ratios for the architecture graduates who had the above demographic factors and gained full-time employment after graduation are were $62.54 \%, 65.94 \%, 66.07 \%$ and $63.66 \%$, as compared to the employment to populations for architecture graduates who were female, below 24 years old, studied undergraduate degrees and spoke other languages at home at $58.14 \%, 55.95 \%, 53.64 \%$ and $49.45 \%$ (see Table 6). The chi-square p-values for gender, age, education level and whether speaking English at home of architecture graduates who were in full-time or part-time employment are 0.00, 0.00, 0.00 and 0.03, which means they are at statistically significant levels (see Table 4). Their phi coefficient values were $0.06,-0.13,-0.15$ and 0.05 which indicates the demographic factors have low to moderate relationship with being in full-time or part-time employment (Field et. al., 2012) (see Figure 2). This finding contrasts with Smith et al.'s (2000) view that younger graduates were more likely to be employed. This may be a specific situation for architecture graduates as they are required to study for a Master Degree, which means the total year of their education is 5 years in the university, before they can be qualified as practice architects.

\section{INSERT TABLE 4 HERE}

\section{INSERT FIGURE 2 HERE}

The chi-square $\mathrm{p}$-value for gender and whether urban planning graduates gained full-time employment was 0.03 , which was at a statistically significant level. The phi coefficient was 0.06 , which showed there was a trivial positive relationship between gender and urban planning graduates' possibility of gaining full-time employment. As the phi coefficient figure was positive, this indicated male urban planning graduates have a slightly higher chance of securing full-time employment. This has also been reinforced by the employment to population ratio of male urban planning graduates gaining a full-time job is $72 \%$ as compared to $71 \%$ for female graduates. The finding of this paper shared the same view as the IER's (1997) finding, which was that male graduates were more likely to gain full-time employment. 
Female urban planning graduates were more likely to work in part-time roles than male graduates. There were $58.49 \%$ of female urban planning graduates working part-time while $41.51 \%$ of those working part-time were male graduates (see Table 5). The employment to population ratio for female urban planning graduates working in part-time roles was $20.00 \%$ as compared to $14.73 \%$ for male graduates (see Table 6). This is in keeping with IER's (1997) finding, which was that females are more likely to work in part-time roles, although the percentage difference is getting smaller. In IER's (1997) study, it reported that $43 \%$ and $2 \%$ of female and male graduates worked in part-time roles. However, the difference in findings between the current and IER's (1997) study is separated by nearly 20 years and so demonstrates a significant shift.

\section{INSERT TABLE 5 HERE}

\section{INSERT TABLE 6 HERE}

Age and whether speaking English at home were statistically significant correlated with whether construction graduates were in full-time or part-time employment. Their chi-square p-values are 0.02 and 0.01 . Their phi coefficient values are -0.06 and 0.07 , which means the construction graduates age 24 years or above and speaking English at home are at a trivial level more likely to be employed on a full-time basis after graduation. The employment to population ratio for the construction graduates gaining a full-time job aged 24 years or above and below 24 are $85.14 \%$ and $83.41 \%$; and the employment to population ratio for the construction graduates who spoke English at home and gained full-time employment is $86.07 \%$ as compared to those who spoke other languages at home at $74.50 \%$.

Please see Table 7 for a summary of research findings.

\section{INSERT TABLE 7 HERE}

\section{Conclusion}

This paper investigated the demographic factors influencing architecture, construction and urban regeneration graduates employment prospects in Australia, including whether they were employed or unemployed and were in full-time or part-time employment. This research also identified the differences in the patterns of graduates who gained employment or not and whether on a full-time or part-time basis. The demographic factors identified in this paper included gender, age, education level and whether they spoke English at home. This paper discussed the development of the dataset from the raw data of the Australian Graduate Survey (AGS) to identify whether they were employed or not and in full-time or part-time employment.

There were 2119 architecture graduates, 1475 construction graduates and 1522 urban planning graduates, who were Australian Permanent Residents and were not continuing on to further study. There was an even distribution of architecture and urban planning graduates of different gender and education levels, but that was not the case for construction graduates, which had $83.19 \%$ male and $85.76 \%$ of them studied an undergraduate degree. There was a higher 
percentage of urban planning graduates aged 24 or above, at $61.76 \%$ while there was a higher percentage of graduates studying undergraduate degree for architecture and construction. The majority of graduates, i.e. more than three-quarters of them among all disciplines, were speaking English at home.

Speaking English at home or not was statistically significant correlated with whether architecture, construction and urban planning graduates' were employed and the chi-square $\mathrm{p}$ values validated this argument. Their relationship is positive as the phi coefficient value is positive. On the other hand, gender, age and education level was not statistically significant correlated with whether graduates were employed or not in all the disciplines studied in this paper.

All demographic factors identified in this paper were statistically significant correlated with architecture graduates employment prospects. Architecture graduates, who were male, aged 24 years or above, studied postgraduate degrees and spoke English at home were statistically more likely to secure full time employment after graduation. Age and whether speaking English at home were also correlated with whether construction graduates were in full-time or part-time employment while gender was correlated with urban planning graduates' opportunities on gaining full-time employment after graduation.

This paper identified some factors which universities can adopt to enhance employment prospects for architecture, construction and urban design graduates. Speaking English at home, is an indicator for English proficiency and it has proved to be one of the important factors contributing to graduate employment. In addition to implement the recruitment strategy which focuses on enrolling students who are native English speakers, universities can take active measures to enhance graduates' English proficiency by offering language courses or writing workshops to students. It is also important to include English proficiency, both speaking and writing, as part of the course learning outcomes in order to ensure students achieve a certain level of language competency before graduation. Furthermore, universities can also consider changing their student recruitment strategy on different courses in order to enhance graduate employability, for example, increase the recruitment of architecture students to study postgraduate courses. If the universities consider it favourable for their graduates to be employed on a full-time basis after graduation, they should also develop strategies which target different gender and age groups. For example, active strategy should be developed to attract older, i.e. 24 or above to study architecture and construction courses and also attract male students to study urban planning courses.

\section{Limitations Of This Research}

The first limitation is that this research has not been able to study some demographic factors affecting graduates' employment which have been identified in the existing literature, prior/ preuniversity qualifications, such as their A-Level results (Smith et al., 2000); social backgrounds, the type of secondary school attended (Lim, 2010; Smith et al., 2000) and marital status (Lim, 2010; Smith et al., 2000) as this information was not captured in Australian Graduate Survey. 
The second limitation of this research is the application of the research findings explaining employment prospects. This paper concluded that certain factors, such as whether speaking English at home or not, gender, age and education level, have correlation to employment prospects of architecture, construction and urban design graduates. However, there is no conclusive note that can be drawn on these factors affecting their employment prospects as there are other factors, as mentioned in the first limitation of this section, which may also have an impact on real estate graduates employment prospects.

The third limitation is the grouping of the age. In this paper, two age groups were presented, which is below 24 or 24 and above. The reason for using aggregate age as dichotomous variables is that it will be able to demonstrate a more accurate statistical relationship of age and employment prospects. This approach is not without limitation. As the age range for 24 and above is very large and to include them as one group may not accurately reflect the impact of age on the employment prospects.

The fourth limitation is the generalizability of the research. The data used in this research is Australian-based data, therefore, this research is dominantly generalizable in Australia only. In other words, the research findings of this paper cannot be widely applicable to other countries. Indeed, the findings of this paper contrast with the findings of similar studies conducted in the UK (Devaney and Roberts, 2012).

The final limitation is caused by the nature of the AGS data. There is no information whether the companies have a preference to employ local or overseas graduates. Therefore, this research cannot establish whether nationality has an impact on graduate employment prospects.

\section{References}

Artess, J., Ball, C. \& Mok, P. (2008). Higher degrees: Postgraduate study in the UK 2000/01 to 2005/06, DIUS Research Report 08-16. London: Department for Innovation, Universities and Skills.

Australian Graduate Survey (AGS) (2015). Australian Graduate Survey [WWW document]. URL http://www.graduatecareers.com.au/research/surveys/australiangraduatesurvey/.

Ballarino, G. (2009). Field of study and university graduates' early employment outcomes in Italy during 1995-2004. Labour, 23 (3), 421-457.

Casplan, S. \& Gilham, J. (2005). Included against the odds: failure and success among minority ethnic built-environment professionals in Britain. Construction Management and Economics, 23, $1007-1015$.

Cohen, J. (1988). Statistical power analysis for the behavioural sciences (2nd ed.). New Jersey: Lawrence Erlbaum.

Connor, H., La Valle, I., Pollard, E. \& Milmore, B. (1997). What do graduates do next? Report 343. London: Institute for Employment Studies. 
Dabalen, A, Bankole, O. \& Olatunde, A.A. (2001). Labour market prospects for university graduates in Nigeria". Higher Education Policy, 14(2), 141-159.

Dainty, A., Bagilhole, B. \& Neale, R. (2000). A grounded theory of women's career underachievement in large UK construction companies. Construction Management and Economics, 18, 239-250.

Department of Education, Science and Training (DEST), Australian Chamber of Commerce Industry (ACCI) \&Business Council of Australia (BCA) (2002). Employability skills for the future. Canberra, Australia.

Department of Industry, Innovation, Climate Change, Science, Research and Tertiary Education (DIICCSRT) \& Department of Education, Employment and Workplace Relations (DEEWR) (2013). Core skills for Work Developmental Framework (CSfW). Canberra, Australia.

Devaney, S. \& Roberts, D. (2012). Who gets the jobs? Factors influencing the employability of property and construction graduates in the UK. Construction Management and Economics, 30, 233-246.

Dickerson, N., Schur, L., Kruse, D. \& Blasi, J. (2010). Worksite segregation and performancerelated attitudes. Work and Occupations, 37(1), 45-72.

Elias, P., McKnight, A., Pitcher, J., Purcell, K. \& Simm, C. (1999). Moving on: Graduate careers three years after graduation. Manchester: Careers Service Unit/Department for Education and Employment.

Field, A., Miles, J., \& Field, Z. (2012). Discovering statistics using R. London: SAGE Publications Ltd.

Fielden, S. L. Davison, M. J., Gale, A. W. \& Davey, C. L. (2000). Women in construction: the untapped resource. Construction Management and Economics, 18, 113-121.

Guerrero, L. \& Posthuma, P. A. (2014). Perceptions and behaviours of Hispanic workers: a review. Journal of Managerial Psychology, 29(6), 616 - 643.

IER (1997). Review of the economy and employment. Institute of Employment research, London: HMSO.

Lan, P-C (2003). They have more money but I speak better English! Transnational encounters between Filipina domestics and Taiwanese employers. Identities: Global Studies in Culture and Power, 10(2), 133-161.

Lim, H. (2010). Predicting low employability graduates: The case of University Utara Malaysia. The Singapore Economic Review, 55 (3), 523-535. 
McKnight, A. (1999). Graduate employability and performance indicators: first destination and beyond; in Moving on: graduate careers three years after graduation. Manchester: DfEE/ IER.

Morgan, G. A., Leech, N. L., Gloeckner, G. W. \& Barrett, K. C. (2013). IBM SPSS for introductory statistics: use and interpretation (5th ed.). New York: Routledge.

Precision Consultancy (2007). Graduate employability skills prepared for the Business, Industry and Higher Education Collaboration Council. Department of Education, Science and Training, Canberra, Australia.

Riordan, C. M. \& Shore, L. M. (1997). Demographic diversity and employee attitudes: an empirical examination of relational demography within work units. Journal of Applied Psychology, 82(3), 342-358.

Smith, J., McKnight, A. \& Naylor, R. (2000). Graduate employability: policy and performance in higher education in the UK. Economic Journal, 110 (June), F382-F411.

Smith, R. J. \& Clark, S. J. (2011). Does job resource loss reduce burnout and job exit for professionally trained social workers in child welfare?. Children and Youth Services Review, 33(10), 1950-1959.

Urwin, P. \& Di Pietro, G. (2005). The impact of research and teaching quality inputs on the employment outcomes of postgraduates. Higher Education Quarterly, 59 (4), 275-295.

Wong, A. M. N. \& Hamali, J. (2006). Higher education and employment in Malaysia. International Journal of Business and Society, 7(1), 102-120. 